\title{
Multiple Intravenous Tranexamic Acid Doses After Open Wedge-high Tibial Osteotomy(OW-HTO) Further Reduce Perioperative Blood Loss and Drainage Volume: A Retrospective Study
}

Zhimeng Wang ( $\nabla$ enshuo99@126.com )

Xi'an Hong Hui Hospital

Yao Lu

Xi'an Hong Hui Hospital

Lu Liu

Xi'an Hong Hui Hospital

Leilei Song

qing hai da xue yi xue yuan: Qinghai University Medical College

Teng Ma

Xi'an Hong Hui Hospital

Zhong Li

Xi'an Hong Hui Hospital

Qian Wang

Xi'an Hong Hui Hospital

Kun Zhang

Xi'an Hong Hui Hospital

Hanzhong Xue

Xi'an Medical University

\section{Research Article}

Keywords: Tranexamic acid, Blood loss, High tibial osteotomy, Multiple, Function

Posted Date: March 18th, 2021

DOI: https://doi.org/10.21203/rs.3.rs-316419/v1

License: (우 (i) This work is licensed under a Creative Commons Attribution 4.0 International License. Read Full License 


\section{Abstract}

Background Studies have demonstrated the effectiveness and safety of tranexamic acid (TXA) in opening wedge high tibial osteotomy(OW-HTO). However, a consensus has not been established regarding the best dosing regimen and timing. In the present study, we aimed to compare three different dosages of intravenous (IV) TXA in OW-HTO.

Material and methods A retrospective analysis of the clinical data obtained from patients administered with OW-HTO treatment for knee osteoarthritis from February 2016 to December 2019 was conducted. All operations were performed under general anaesthesia. TXA1 group (18 patients) received $1 \mathrm{~g}$ of IV TXA administered 15 to 30 minutes pre-operation. TXA2 group (18 patients) received an additional dose of IV TXA (1g) $3 \mathrm{~h}$ after incision and the TXA3 group (18 patients) received an additional (third) dose $6 \mathrm{~h}$ later(1g). The blood loss and adverse events were compared between the three groups. Functional analysis, quality of life (QoL), and pain assessment were performed based on their corresponding scoring system.

Results Baseline data were comparable for all groups. The postoperative drainage volume was calculated for the TXA3 group and the estimated blood loss was significantly reduced ( $p$-value $<0.05)$. The treatment effectively maintained postoperative $\mathrm{Hb}$ at a high level ( $\mathrm{p}$-value $<0.05$ ). In addition, a faster recovery, better QoL, reduced postoperative pain, and no complications were observed in patients belonging to the group TXA3.

Conclusion Based on our results, three doses of IV TXA can effectively and safely reduce estimated blood loss and postoperative drainage volume in patients undergoing OW-HTO with additional associated benefits.

\section{Introduction}

Knee osteoarthritis $(\mathrm{KOA})$ is a common and frequently-occurring disease in elderly patients ${ }^{1}$. With continuous advances in clinical and basic research, the step treatment plan implemented by the majority of doctors and widely accepted by patients along with high tibial osteotomy (HTO) is garnering interest. ${ }^{2-4}$ Compared with the traditional closing wedge-HTO (CW-HTO), the opening wedge-HTO (OW-HTO) has low adverse events and high survival rates associated with it. Hence, it is considered one of the most effective methods for the treatment of $\mathrm{KOA}^{5-7}$. However, owing to the use of tourniquets, exfoliation of soft tissues, and exposure of the cancellous bone surface during osteotomy, intraoperative and postoperative bleeding is inevitable and may lead to significant bleeding ${ }^{8-10}$. Postoperative bleeding can cause hematomas around the incision, delayed incision healing, deep infections, and anemia ${ }^{11}$. Patients with massive blood loss require the allogeneic blood transfusion, which can lead to adverse reactions such as fever, infection, allergic reactions, and hemolysis ${ }^{12}$. Therefore, exploring for an effective method to reduce bleeding following OW-HTO is an important research direction.

As an important part of blood management, anti-fibrinolytic therapy has attracted the attention of researchers and clinicians. Tranexamic acid (TXA) as a traditional anti-fibrinolytic drug can effectively reduce the perioperative blood transfusion rate, dominant and hidden blood loss, and does not increase the risk of deep vein thrombosis(DVT). Hence, it has become the gold standard for perioperative blood management ${ }^{13,14}$. Previous studies have focused on orthopaedic and spinal operations and have confirmed that TXA can 
maintain the physiological hemostasis. ${ }^{15,16}$. However, few studies have been evaluating the application of TXA in OW-HTO. Hence, there is an absence of consensus over the optimal regimen and timing9,17-19.

In previous studies, a single dose intravenous TXA was the most common regimen, which leads to less drainage volume and total blood loss compared to effects observed in the control group ${ }^{18,19}$. Collectively, the TXA pharmacokinetic studies demonstrate the half-life of approximately three hours and the peak of fibrinolysis in major orthopaedic surgery as approximately six hours post-operatively ${ }^{20}$. We believe that a single intravenous dose is not effective in reducing perioperative total blood loss and postoperative drainage volume. Therefore, a trial was conducted at our institution to answer the following questions: (1) Can multiple-dose IV TXA further reduce total perioperative blood loss / postoperative drainage volume? (2) Does multi-dose IV TXA have any additional advantages in functional recovery, quality of life (QoL), and pain reduction during postoperative rehabilitation? (3) Will multiple doses of TXA cause more thromboembolic events?

\section{Materials And Methods}

\section{Patients}

This study retrospectively analysed clinical data of patients who underwent OW-HTO surgery performed by one author (KZ) from January 2016 to December 2019. A total of 62 patients were enrolled in the study. The inclusion criteria were determined as follows: (1) patients with symptomatic medial osteoarthritis, (2) age 40-70 years, (3) underwent OW-HTO surgery for unilateral osteoarthritis, (4) no coagulopathy and abnormal haemoglobin observed prior to the operation. The exclusion criteria were determined as follows: (1) patients with severe brain, heart, liver, and kidney dysfunction who cannot tolerate surgery, (2) patients with blood system diseases; (3) traumatized knee prior to the surgery, (4) patients undergoing bilateral OW-HTO surgery, (5) contraindications for use of TXA or anticoagulant drugs, (6) patients with incomplete medical data/history will be excluded. In addition, when the surgeon filled the osteotomy space with an autologous bone graft during surgery, the data were excluded from the statistical analysis, as the extra wound incision and blood loss from the iliac bone could have affected the results.

\section{Intervention}

Based on the established inclusion and exclusion criteria, 18 patients were recruited for the single-dose group (TXA1), two-dose group (TXA2), and three-dose group (TXA3) each. The single-dose group was administered treatment from February 2016 to November 2016, and a total of $1 \mathrm{~g}$ of TXA was injected intravenously 15 to 30 minutes before operation. The two-dose group was administered treatment from December 2017 to November 2018. The amount administered to the single-dose group was considered as the base dose, and another $1 \mathrm{~g}$ of TXA was intravenously infused again $3 \mathrm{~h}$ post surgery. The three-dose group was treated from December 2018 to December 2019. The treatment amount administered to the two-dose group was considered as the base dose, and another $1 \mathrm{~g}$ of TXA was intravenously infused again $6 \mathrm{~h}$ after surgery. In previous studies, a single IV TXA demonstrated the advantages of reducing postoperative blood loss and drainage volume over the control group. Hence, a control group was not recruited for this study. 


\section{Surgical Methods and Postoperative Management}

The drugs were administered under general anaesthesia were common among the three groups. The pressure of the balloon-type tourniquet of the affected limb was set to $450 \mathrm{mmHg}$, and the mean arterial blood pressure (MAP) was maintained at $60870 \mathrm{mmHg}$. The surgical technique was performed as per the previous study 5,7,21. Briefly, based on the full-length positive X-rays of the lower extremities and the lateral X-rays of the knee joints, the Miniaci method was used for the preoperative design, planning the osteotomy orthopaedic angle and the expansion distance, so that the weight-bearing axis of the lower limbs passed $62 \%$ of the outside of the knee joint line, i.e., the lateral slope of the intercondylar ridge of the tibia. This point is known as the Fujisawa point. A $5 \mathrm{~cm}$ longitudinal incision was made on the medial side of the knee joint to loosen the superficial layer of the medial collateral ligament. The $\mathrm{C}$-arm X-ray machine fluoroscopically guided the position and direction of the osteotomy with the Kirschner wire; the lateral hinge was located at the level of the upper tibiofibular joint. A bony hinge $1 \mathrm{~cm}$ lateral to the knee was constructed using a biplanar osteotomy with a matching osteotomy orthopaedic tool to slowly open it to avoiding the fracture of the lateral hinge. The osteotomy space treatment methods included boneless transplantation, autogenous bone transplantation, allogeneic bone transplantation, bone replacement materials and factor transplantation to enhance bone healing. During the operation, under the C-arm X-ray machine fluoroscopy, the mechanical axis of the lower extremity was adjusted to be at the Fujisawa point followed by placing an appropriate internal fixator for the mechanical support of the osteotomy space, followed by incision and suture drainage. The surgery was concluded. The leg was raised 3 to 4 days post-operation, and drainage tubes were removed within $48 \mathrm{~h}$. Functional exercise of the active and passive range of motion was started at the first postoperative day (POD\#1), the partial weight-bearing exercise under the guidance of a physician on the second postoperative day (POD\#2). The full weight-bearing exercise under the guidance of a physician was performed on the fifth postoperative day (POD\#5). The RBC transfusion indications formulated by our institution are as follows: $\nabla \mathrm{Hb}<70 \mathrm{~g} / \mathrm{L} ; \nabla 70 \mathrm{~g} / \mathrm{L}<\mathrm{Hb}<100 \mathrm{~g} / \mathrm{L}$. Symptoms of dizziness, palpitation, asthma, and lassitude were observed in the patients.

\section{Study Objectives}

\section{Background}

The following demographic data were recorded for each patient: gender, age, body mass index, medical history, American Society of Anesthesiologists score ${ }^{22}$ (ASA), time of disease course, Kellgren-Lawrence grade ${ }^{23}$, preoperative blood volume (PBV), preoperative haemoglobin $(\mathrm{Hb})$, preoperative hematocrit ( $\mathrm{Hct})$, preoperative Ddimer, preoperative fibrinogen (FIB).

\section{Postoperative data}

The duration of surgery and hospitalization, drainage volume, total blood loss, and transfusion rate were also included in the statistics. Furthermore, routine blood tests and coagulation tests (such as Hb,Hct, D-dimer, FIB, APTT, and PT) were evaluated POD\#1 and POD\#3. In order to evaluate the safety of TXA in this study, the following parameters were examined. Any vascular event occurring within 12 weeks after surgery, including 
deep vein thrombosis (DVT) of the lower extremity confirmed by ultrasound, pulmonary embolism (PE) confirmed by pulmonary spiral CT, cerebrovascular accidents confirmed by spiral CT or MRI, and gastrointestinal haemorrhage. We recorded the incidence of wound complications (such as dehiscence, hematoma, edge necrosis, and infection). Potential adverse side effects of TXA such as epilepsy, rash, headache, nausea, and vomiting were also recorded ${ }^{24,25}$.

\section{Functional, QoL, and Pain analysis}

Pre-operative knee function, QoL, and pain were in the patient were assessed with the Lysholm knee score (LKS), the 12-items Short Form Health Survey (SF-12), and the visual analog scale (VAS) of pain, respectively ${ }^{26-}$ 28. LKS, SF-12, VAS pain tests were repeated at 6 th week and 12th-week during post-operative routine outpatient visits. VAS pain test was further assessed on the second and fourth postoperative days.

\section{Calculation of perioperative blood loss}

Total postoperative drainage is the volume of fluid collected in the drainage bag within 48 hours. The postoperative drainage volume can intuitively reflect the postoperative blood loss, especially the dominant blood loss.

Primarily, the preoperative blood volume (PBV) was calculated by Nadler's equation ${ }^{29}$, PBV $(\mathrm{L})=\mathrm{K} 1 \times \mathrm{h} 3+\mathrm{K} 2 \times$ $\mathrm{w}+\mathrm{K} 3$, [h: height $(\mathrm{m})$, w: weight $(\mathrm{kg})]$; male patients $\mathrm{K} 1=0.366$ 9, $\mathrm{K} 2=0.03219, \mathrm{~K} 3=0.6041$; female patients $\mathrm{K} 1=0.3561, \mathrm{~K} 2=0.03308, \mathrm{~K} 3=0.183319$.

Subsequently, the estimated blood loss (EBL) was calculated according to the Gross equation ${ }^{30}$ $\mathrm{EBL}(\mathrm{ml})=\mathrm{PBV} \times\left(\mathrm{Hct}_{1}-\mathrm{Hct}_{2}\right) / \mathrm{Hct}_{\mathrm{av}} \cdot \mathrm{Hct}_{1}$ is the first routine blood test after the patient admitted to the hospital; $\mathrm{Hct}_{2}$ is the lowest postoperative value obtained by routine blood tests; $\mathrm{Hct}_{\mathrm{av}}$ is the mean of $\mathrm{Hct}_{1}$ and $\mathrm{Hct}_{2}$.

\section{Statistical Analysis}

Statistical analyses were performed using GraphPad Prism 8.0. Continuous variables were reported as mean and standard deviation. One-way analysis of variance (ANOVA) was used to compare the differences among multiple groups. The Student's t-test was utilized to compare the differences between the two groups. A Chisquare test was used for the analysis of categorical data. P-value $<0.05$ was considered statistically significant.

\section{Results}

\section{Patient background data (Table 1)}

Routine follow-ups were conducted for all 54 patients included in the study up to 12 weeks post-operation,the data was not lost during the follow-up for any patient. No statistically significant differences were observed in 
patient demographics or preoperative blood tests. In addition, preoperative functional tests, quality of life, and pain scores in the three groups were comparable and not statistically different.

Table 1

Patient's demographic data and preoperative blood test

\begin{tabular}{|c|c|c|c|c|}
\hline Variable & $\begin{array}{l}\text { TXA1 } \\
\text { (18 patients) }\end{array}$ & $\begin{array}{l}\text { TXA2 } \\
\text { (18 patients) }\end{array}$ & $\begin{array}{l}\text { TXA3 } \\
\text { (18 patients) }\end{array}$ & $\begin{array}{l}P \text { value } \\
\text { (between group) }\end{array}$ \\
\hline \multicolumn{5}{|l|}{ Patient characteristics } \\
\hline Age (yr) & $54.63 \pm 6.71$ & $57.81 \pm 5.53$ & $55.15 \pm 6.17$ & $0.250^{\mathrm{a}}$ \\
\hline Gender(male/female) & $6 / 12$ & $5 / 13$ & $8 / 10$ & $0.566^{\mathrm{b}}$ \\
\hline BMI & $23.33 \pm 2.41$ & $24.92 \pm 2.54$ & $23.56 \pm 1.94$ & $0.082^{\mathrm{a}}$ \\
\hline \multicolumn{5}{|l|}{ Medical history } \\
\hline Diabetes mellitus & 1 & 1 & 1 & \multirow[t]{3}{*}{$0.864^{b}$} \\
\hline Hypertension & 3 & 1 & 2 & \\
\hline Arrhythmia & 1 & 2 & 2 & \\
\hline \multicolumn{5}{|l|}{ ASA score } \\
\hline$\square$ & 10 & 11 & 13 & \multirow[t]{3}{*}{$0.842^{b}$} \\
\hline ૧ & 6 & 6 & 4 & \\
\hline$\square$ & 2 & 1 & 1 & \\
\hline $\mathrm{Hb}(\mathrm{g} / \mathrm{L})$ & $132.13 \pm 11.01$ & $129.32 \pm 9.23$ & $131.15 \pm 10.33$ & $0.714^{\mathrm{a}}$ \\
\hline Hct (\%) & $40.16 \pm 3.14$ & $38.33 \pm 2.75$ & $39.14 \pm 2.16$ & $0.138^{a}$ \\
\hline D-dimer (mg/L) & $0.23 \pm 0.10$ & $0.25 \pm 0.10$ & $0.17 \pm 0.10$ & $0.053^{a}$ \\
\hline $\mathrm{FIB}(\mathrm{g} / \mathrm{L})$ & $3.26 \pm 0.61$ & $3.43 \pm 0.59$ & $3.18 \pm 0.42$ & $0.382^{a}$ \\
\hline \multicolumn{5}{|c|}{$\begin{array}{l}\text { Abbreviations: BMI, Body mass index; ASA, American Society of Anesthesiologists; Hb, Hemoglobin; Hct, } \\
\text { Hematocrit; FIB, fibrinogen. }\end{array}$} \\
\hline \multicolumn{5}{|c|}{ Intergroup comparisons performed using AVONA or Chi-square test ( ${ }^{\mathrm{a} A N O V A}$; ${ }^{\mathrm{b}}$ Chi-square test). } \\
\hline
\end{tabular}

\section{Duration of surgery and hospitalization (Table 2)}

The mean values of the duration of operative in the TXA1, TXA2, and TXA3 groups were $137.23 \mathrm{~min}, 139.41$ min, 125.83 min, respectively, with no significant intergroup differences $(P=0.063)$. In addition, there was no 
statistically significant difference in hospitalization days between the three groups $(P=0.456)$. This may be associated with the fact that the patients cannot be discharged after major orthopaedic surgery cannot be prescribed sooner than the fifth postoperative day at our institution.

\section{Table 2}

Postoperative date and postoperative blood test 


\begin{tabular}{|c|c|c|c|c|c|c|c|}
\hline \multirow[t]{2}{*}{ Variable } & \multirow{2}{*}{$\begin{array}{l}\text { TXA1 } \\
\text { (18 patients) }\end{array}$} & \multirow{2}{*}{$\begin{array}{l}\text { TXA2 } \\
\text { (18 patients) }\end{array}$} & \multirow{2}{*}{$\begin{array}{l}\text { TXA3 } \\
\text { (18 patients) }\end{array}$} & \multirow[t]{2}{*}{$P$ value } & \multicolumn{3}{|c|}{ Intergroup comparison } \\
\hline & & & & & $P_{1}$ & $P_{2}$ & $P_{3}$ \\
\hline $\begin{array}{l}\text { Duration of } \\
\text { surgery (min) }\end{array}$ & $137.23 \pm 16.34$ & $139.41 \pm 17.55$ & $125.83 \pm 20.15$ & $0.063^{\mathrm{a}}$ & - & - & - \\
\hline $\begin{array}{l}\text { Hospitalization } \\
\text { days (d) }\end{array}$ & $7.74 \pm 1.20$ & $7.95 \pm 1.35$ & $7.45 \pm 1.00$ & $0.456^{\mathrm{a}}$ & - & - & - \\
\hline $\begin{array}{l}\text { Drainage } \\
\text { volume }(\mathrm{ml})\end{array}$ & $146.35 \pm 37.66$ & $121.57 \pm 35.28$ & $74.13 \pm 26.93$ & $<0.001^{\mathrm{a}}$ & 0.049 & $<0.001$ & $<0.001$ \\
\hline $\begin{array}{l}\text { Estimated } \\
\text { blood loss (ml) }\end{array}$ & $393.56 \pm 54.27$ & $347.44 \pm 60.54$ & $311.36 \pm 43.14$ & $<0.001^{a}$ & 0.022 & $<0.001$ & 0.047 \\
\hline \multicolumn{8}{|l|}{$\begin{array}{l}\text { Postoperative } \\
\text { blood tests }\end{array}$} \\
\hline \multicolumn{8}{|l|}{$\mathrm{Hb}(\mathrm{g} / \mathrm{L})$} \\
\hline POD\#1 & $112.65 \pm 12.23$ & $117.51 \pm 11.12$ & $123.46 \pm 10.84$ & $0.022^{\mathrm{a}}$ & 0.221 & 0.007 & 0.108 \\
\hline POD\#3 & $113.17 \pm 10.14$ & $117.89 \pm 9.34$ & $124.45 \pm 10.42$ & $0.005^{\mathrm{a}}$ & 0.156 & 0.002 & 0.055 \\
\hline \multicolumn{8}{|l|}{ Hct (\%) } \\
\hline POD\#1 & $31.05 \pm 4.13$ & $31.41 \pm 3.39$ & $33.47 \pm 2.14$ & $0.072^{\mathrm{a}}$ & - & - & - \\
\hline POD\#3 & $31.57 \pm 3.69$ & $32.16 \pm 2.54$ & $34.12 \pm 3.61$ & $0.064^{\mathrm{a}}$ & - & - & - \\
\hline \multicolumn{8}{|l|}{$\begin{array}{l}\text { D-dimer } \\
(\mathrm{mg} / \mathrm{L})\end{array}$} \\
\hline POD\#1 & $1.96 \pm 0.74$ & $2.01 \pm 1.09$ & $1.74 \pm 0.63$ & $0.596^{\mathrm{a}}$ & - & - & - \\
\hline POD\#3 & $1.42 \pm 0.61$ & $1.58 \pm 0.72$ & $1.13 \pm 0.60$ & $0.116^{\mathrm{a}}$ & - & - & - \\
\hline \multicolumn{8}{|l|}{ Fib (g/L) } \\
\hline POD\#1 & $3.67 \pm 1.21$ & $3.51 \pm 1.39$ & $3.04 \pm 0.93$ & $0.266^{\mathrm{a}}$ & - & - & - \\
\hline POD\#3 & $3.54 \pm 1.16$ & $3.24 \pm 1.43$ & $2.78 \pm 0.87$ & 0.264 & - & - & - \\
\hline $\begin{array}{l}\text { Transfusion } \\
\text { rate } ₫ \% \rrbracket\end{array}$ & $5.56 \%$ & 0 & 0 & $0.361^{b}$ & - & - & - \\
\hline \multicolumn{8}{|c|}{ Abbreviations: POD\#1, the first postoperative day ;POD\#3, the third postoperative day. } \\
\hline \multicolumn{8}{|c|}{$P_{7}$ represents the $\mathrm{p}$ value obtained by comparison between TXA1 and TXA2; } \\
\hline \multicolumn{8}{|c|}{$P_{2}$ represents the $p$ value obtained by comparison between TXA1 and TXA3; } \\
\hline \multicolumn{8}{|c|}{$P_{3}$ represents the $p$ value obtained by comparison between TXA2 and TXA3; } \\
\hline Intergroup comp & risons performe & using AVONA or & Chi-square test & NOVA ; & & test). & \\
\hline
\end{tabular}




\section{Blood tests (Table 2)}

The results of routine blood tests and blood coagulation tests in the three groups are summarized in Table 2. In the TXA1, TXA2, and TXA3 groups, the mean values of postoperative Hb (the POD\#1) were 112.65 \pm 12.23 , $117.51 \pm 11.12$, and $123.46 \pm 10.84 \mathrm{~g} / \mathrm{L}$, respectively with a significant intergroup difference $(p=0.022)$. Similarly, the mean values of $\mathrm{Hb}$ on POD\#3 were $113.17 \pm 10.14,117.89 \pm 9.34,124.45 \pm 10.42 \mathrm{~g} / \mathrm{L}$, with significant differences between the three groups $(p=0.005)$.

However, the D-dimer and FIB mean values did not differ significantly on POD\#1 and POD\#3.

\section{Total blood loss, drainage volume, and transfusion (Figure 2)}

After careful calculation and verification, significant differences were observed in EBL between three groups $(p<0.001)$. Statistically significant differences were observed for TXA1 VS TXA2 $(p=0.022)$, TXA1 VS TXA3 $(p<0.001)$, TXA2 VS TXA3 $(p=0.047)$ via pairwise comparison and statistical analysis. The same result was also demonstrated in the drainage volume in TXA1, TXA2, and TXA3 group were $146.35 \pm 37.66,121.57 \pm 35.28,74.13 \pm 26.93 \mathrm{ml}$ respectively with intergroup $p$-value $<0.001$.

The final statistical results demonstrated that a patient in the TXA1 group was transfused with two units of PRBCs owing to the postoperative anemia symptoms, while no patients in TXA2 and TXA3 group required blood transfusion. No statistical difference in the transfusion rate was observed between the three groups $(p=0.361)$.

\section{Vascular events, wound complications, and adverse reactions (Table 3)}

In this study, the venous plexus of calf muscle was the most common site for DVT, followed by the popliteal vein. No severe complications such as pulmonary embolism, myocardial infarction, and cerebral infarction were observed. No significant differences in wound complications and adverse reactions were observed between the three groups. The associated data are described in Table 3.

Table 3

Vascular events, Wound complications and adverse reactions of TXA 


\begin{tabular}{|c|c|c|c|c|}
\hline Variable & $\begin{array}{l}\text { TXA1 } \\
\text { (30 patients) }\end{array}$ & $\begin{array}{l}\text { TXA2 } \\
\text { (30 patients) }\end{array}$ & $\begin{array}{l}\text { TXA3 } \\
\text { (30 patients) }\end{array}$ & $\begin{array}{l}P \text { value } \\
\text { (between group) }\end{array}$ \\
\hline \multicolumn{5}{|l|}{ Vascular events } \\
\hline DVT & 2 & 1 & 1 & 0.763 \\
\hline $\mathrm{Ml}$ & 0 & 0 & 0 & - \\
\hline $\mathrm{Cl}$ & 0 & 0 & 0 & - \\
\hline PE & 0 & 0 & 0 & - \\
\hline GIH & 0 & 0 & 0 & - \\
\hline Total & 2 & 1 & 1 & 0.763 \\
\hline \multicolumn{5}{|l|}{ Wound complications } \\
\hline Dehiscence & 0 & 0 & 0 & - \\
\hline Hematoma & 1 & 0 & 0 & 0.361 \\
\hline Edge necrosis & 1 & 0 & 0 & 0.361 \\
\hline Infection & 0 & 0 & 0 & - \\
\hline Total & 2 & 1 & 0 & 0.347 \\
\hline \multicolumn{5}{|l|}{ Adverse reactions } \\
\hline Epilepsy & 0 & 0 & 0 & - \\
\hline Rash & 0 & 0 & 0 & - \\
\hline Headache & 1 & 1 & 2 & 0.763 \\
\hline Nausea and Vomiting & 0 & 1 & 1 & 0.595 \\
\hline Total & 1 & 2 & 3 & 0.570 \\
\hline \multicolumn{5}{|c|}{$\begin{array}{l}\text { Abbreviations: TXA, tranexamic acid; DVT, deep vein thrombosis; Ml, myocardial infarction; } \mathrm{Cl} \text {, cerebral } \\
\text { infarction; PE, pulmonary embolism; GIH, gastrointestinal hemorrhage. }\end{array}$} \\
\hline
\end{tabular}

\section{Functional, QoL and pain assessment (Figure 3,4,5)}

We used the Lysholm knee score to evaluate knee function in the patients after the operation. The results demonstrated that the LKS score of the three groups in the follow-ups was not statistically significant. The TXA3 group has an advantage in controlling postoperative pain. However, this advantage is limited to the early postoperative period (POD\#2 and POD\#4, p-value 0.005, and 0.014). 
The SF-12 questionnaire was used to assess changes in QoL both preoperatively and postoperatively. The results demonstrated a significant difference in the PCS values between the three groups after 6 and 12 weeks post surgery ( $p$-value: 0.049 and 0.034 , respectively). No difference in the MCS scores was observed among the three groups.

Table 4

Summary of studies evaluating the use of TXA in OW-HTO

\begin{tabular}{|c|c|c|c|c|c|}
\hline Study & $\begin{array}{l}\text { No. } \\
\text { Patients }\end{array}$ & $\begin{array}{l}\text { Surgical } \\
\text { plan }\end{array}$ & Intervention & $\begin{array}{l}\text { Observation } \\
\text { index }\end{array}$ & Follow-up items \\
\hline Suh DW ${ }^{9}$ & 15 & $\begin{array}{l}\text { OW- } \\
\text { HTO }\end{array}$ & $\begin{array}{l}\text { Topical TXA }(2 \mathrm{~g} \text { in } \\
20 \mathrm{~mL} \text { saline })\end{array}$ & $\begin{array}{l}\mathrm{Hb} \text { and } \\
\text { Drainage } \\
\text { volume }\end{array}$ & - \\
\hline $\mathrm{Kim} \mathrm{Kl^{19 }}$ & 75 & $\begin{array}{l}\text { OW- } \\
\text { HTO }\end{array}$ & $\begin{array}{l}\text { IV TXA (10mg/kg, } \\
\text { three dose) }\end{array}$ & $\begin{array}{l}\text { Hb,Drainage } \\
\text { volume and } \\
\text { EBL }\end{array}$ & DVT and PE in 3 months \\
\hline \multirow{2}{*}{$\begin{array}{l}\text { Palanisamy } \\
\text { JV }^{18}\end{array}$} & \multirow[t]{2}{*}{67} & \multirow{2}{*}{$\begin{array}{l}\text { OW- } \\
\text { HTO }\end{array}$} & \multirow{2}{*}{$\begin{array}{l}\text { IV TXA (2g, two } \\
\text { dose) }\end{array}$} & TBL,HB, & \multirow[t]{2}{*}{ - } \\
\hline & & & & $\begin{array}{l}\text { Hct and } \\
\text { Drainage } \\
\text { volume }\end{array}$ & \\
\hline \multirow[t]{2}{*}{$\mathrm{Li} \mathrm{S}^{8}$} & \multirow[t]{2}{*}{45} & \multirow{2}{*}{$\begin{array}{l}\text { OW- } \\
\text { HTO }\end{array}$} & \multirow{2}{*}{$\begin{array}{l}\text { IV TXA }(1 \mathrm{~g}) / \mathrm{IV} \\
\text { combined with } \\
\text { topical }(1 \mathrm{~g} \\
\text { combined with } 2 \mathrm{~g})\end{array}$} & $\mathrm{TBL}, \mathrm{Hb}$ & \multirow[t]{2}{*}{-} \\
\hline & & & & $\begin{array}{l}\text { Hct,FIB,D- } \\
\text { dimer,TBL } \\
\text { and } \\
\text { Drainage } \\
\text { volume }\end{array}$ & \\
\hline \multirow{2}{*}{$\begin{array}{l}\text { Current } \\
\text { study }\end{array}$} & \multirow[t]{2}{*}{54} & \multirow{2}{*}{$\begin{array}{l}\text { OW- } \\
\text { HTO }\end{array}$} & \multirow{2}{*}{$\begin{array}{l}\text { IV TXA (1g, } \\
\text { one/two/three } \\
\text { dose) }\end{array}$} & $\mathrm{Hb}$ & \multirow{2}{*}{$\begin{array}{l}\text { Vascular events, Wound } \\
\text { complications, adverse } \\
\text { reactions,VAS pain,LKS and } \\
\text { QoL in } 12 \text { weeks }\end{array}$} \\
\hline & & & & $\begin{array}{l}\text { Hct,FIB,D- } \\
\text { dimer,EBL } \\
\text { and } \\
\text { Drainage } \\
\text { volume }\end{array}$ & \\
\hline
\end{tabular}

\section{Discussion}

The effect of TXA on blood loss and subsequent complications after OW-HTO have been well described in the previous studies. Therefore, further reduction of the drainage volume and total blood loss after OW-HTO has been an important directive. The purpose of this study was to determine whether the multiple intravenous TXA regimen is the most effective and safe, not only analyzing the results from the perspective of total blood loss and drainage volume with an additional detailed assessment.

The primary results obtained in this study indicate that the multiple doses of TXA can effectively maintain postoperative $\mathrm{Hb}$ values in patients, reduce estimated blood loss volume as well as the drainage volume. 
Compared with the reduction observed from a single dose, two doses can reduce estimated blood loss by approximately $46.12 \mathrm{ml}$, and three doses can reduce the total blood loss by approximately $82.20 \mathrm{ml}$. Drainage volume was reduced by approximately $24.78 \mathrm{ml}$ in the two-dose group and approximately $72.77 \mathrm{ml}$ in the threedose group. Particularly, patients belonging in the three-dose group had more advantages during the postoperative rehabilitation period along with early pain reduction and better QoL, without the increase in the incidence of postoperative vascular events, incision complications, and adverse reactions.

The advantages of TXA in OW-HTO have been proven in many retrospective studies and elaborate metaanalysis ${ }^{8,9,17-19}$. As a traditional antifibrinolytic drug, TXA has proven its effectiveness whether administered intravenously, topically, or in combination. Kim et al. ${ }^{19}$ injected TXA intravenously at a dose of $10 \mathrm{mg} / \mathrm{kg}$ before and 6 hours after tourniquet application, and 24 hours after surgery. The results demonstrated that the haemoglobin level in the TXA group was higher than that in the control group on days 1, 2, and 5 after surgery $(P<0.001)$. Moreover, the total drainage volume and total blood loss were lower than those in the control group $(P<0.001)$. Compared with the results from the above study, the current trial had a shorter and denser intravenous administration gap. Therefore, the study had a theoretical advantage in suppressing early postoperative fibrinolysis, thereby reducing postoperative blood loss and drainage volume. Our results confirm the superiority of the current treatment regimen compared to the treatment administered in the above study. The blood loss and postoperative drainage volume were reduced to approximately $191 \mathrm{ml}$ and $195 \mathrm{ml}$, respectively. Regarding the advantages of multi-dose intravenous TXA, some scholars have reached an optimistic conclusion for TKA without tourniquet ${ }^{20}$. They observed that the use of multi-dose intravenous TXA does not increase extra blood loss during surgery, and demonstrates a huge advantage during early rehabilitation.

The safety of TXA during the perioperative period of major orthopaedic surgery has been a controversial topic. Hence, it has also slowed down the pace of clinical promotion of TXA ${ }^{31,32}$. Compared with the cerebral infarction and gastrointestinal bleeding, more safety concerns are associated with DVT and PE. Although some scholars have pointed out that the incidence of DVT and PE in Asians is significantly lower than in Europeans and Americans, the incidence is still higher with the major surgery of lower extremity orthopaedics. Hence, the problem deserves our attention ${ }^{33}$. At present, most orthopaedic clinical trials are designed to test the haemostatic effect of TXA instead of safety. For rare complications such as pulmonary embolism, the current clinical trial sample size cannot reach a definitive conclusion. However, a large retrospective study from China (including 1907 THA / 1505 TKA) concluded that TXA reduced blood transfusion rates without increasing the prevalence of DVT/PE ${ }^{34}$. In this study, we used a combination of mechanical compression devices and chemical drugs to prevent thromboembolic events, and the results obtained were consistent with the above study. Therefore, we suggest that with reasonable intervention after OW-HTO, the administration of multiple intravenous TXA doses does not demonstrate an increase in the risk of thrombotic events.

In this study, none of the three groups of patients had incision complications and adverse reactions from TXA. Some studies have confirmed that the plasmin not only promotes the activation of monocytes, platelets, and endothelial cells but also plays an important role in stimulating the release of inflammatory mediators as well as inducing the expression of related pro-inflammatory genes ${ }^{35,36}$. TXA inhibits plasmin. Hence, it can exert potential anti-inflammatory effects. In addition, a study has shown that reducing the perioperative blood transfusion rate can reduce the incidence of wound complications ${ }^{37}$. However, the comparison of transfusion 
rates between inter-group in this study demonstrated that the results were not statistically significant and the sample size was small. Hence, no conclusions can be drawn.

Tzatzairis et al. ${ }^{20}$ observed that three doses of IV TXA in TKA can achieve higher knee function and quality of life, and significantly reduce pain in the early and late postoperative periods. Palanisamy et al. ${ }^{18}$ observed that in the OW-HTO of IV TXA, the VAS score of the TXA group was lower than that of the control group on the second day after surgery but had no clinical significance as the difference was small. Li et al. ${ }^{8}$ observed that the combined intravenous and local TXA protocol did not effectively improve knee HSS and VAS scores in patients after surgery (with the 6th month as the observation point). A recent study demonstrated that the use of a drainage tube does not increase the extra blood loss when TXA is used intravenously, and the VAS score and calf swelling in the early postoperative period are lower than those in the control group, which can effectively reduce the incidence of incision complications ${ }^{10}$. The TXA multiple-dose regimen has been confirmed in the current study. Interestingly, the three-dose regimen can well alleviate the early postoperative pain in the patients and can help the patients to exercise knee joint mobility as soon as possible. Early knee function recovery and improvement of pain are favorable factors for predicting the quality of life after OW-HTO. This explains the reason for a higher SF-12 PCS score in the three-dose group since the early postoperative period.

Certain limitations can be attributed to this study. First, the sample size of this study was small, and the study was conducted at a single center. Prospective large-scale, randomized case-control studies are required to confirm these findings. Second, according to the perioperative rehabilitation guidelines for major orthopaedic surgery designated by our institution, all patients received preventive anticoagulation after admission, which might have an impact on postoperative blood loss. Third, given the effectiveness and safety of TXA in previous studies, patients were not recruited in the control group.

\section{Conclusion}

For OW-HTO, the multiple intravenous doses of tranexamic acid are reasonable, safe, and effective. Besides, the tranexamic acid three-dose regimen can more effectively maintain the postoperative hemoglobin value, which is conducive to pain reduction, functional recovery, and a higher QoL score in the early postoperative period.

\section{Abbreviations}

TXA,tranexamic acid;IV, intravenous;KOA,knee osteoarthritis;HTO, high tibial osteotomy;CW-HTO, closing wedgeHTO;OW-HTO, opening wedge-HTO;QoL, quality of life;DVT, deep vein thrombosis ; MAP, mean arterial blood pressure; ASA, American Society of Anesthesiologists score; Hb, hemoglobin;Hct, hematocrit;FIB, fibrinogen; BMI, body mass index;VAS, visual analogue scale;PE, pulmonary embolism; EBL, estimated blood loss; PBV, preoperative blood volume;MI, myocardial infarction; $\mathrm{Cl}$, cerebral infarction; $\mathrm{GIH}$, gastrointestinal hemorrhage,LKS,Lysholm knee score;PCS,Physical health score; MCS, mental health score.

\section{Declarations}

\section{Ethics approval and consent to participate}


Approval was obtained from the Clinical Trials and Biomedical Ethics Committee of The Second Affiliated Hospital of Xi'an Medical College(Approval Number: 2016002), and written informed consent was obtained from all participants.

\section{Consent for publication}

Not applicable.

\section{Availability of data and material}

All data generated or analysed during this study are included in this published article.

\section{Competing interests}

The authors declare no conflict of interest.

\section{Funding}

This study was supported by Project of Science and Technology Department of Shaanxi Province (No. 2016SF017).

\section{Authors' contributions}

$\mathrm{XHZ}$ and $\mathrm{KZ}$ were responsible for the study design, the definition of intellectual content, and for literature research. ZMW $\triangle Y L Z$ and LL analyzed and interpreted data. LLS and TM performed the statistical analysis. ZMW $\otimes Y L$ and QW drafted the manuscript. TM, LL and ZL revised the manuscript. All authors read and approved the final manuscript.

\section{Acknowledgement}

This work was supported by the Project of Science and Technology Department of Shaanxi Province (2016SF017).

\section{References}

1. Maradit Kremers H, Larson DR, Crowson CS, et al. Prevalence of Total Hip and Knee Replacement in the United States. J Bone Joint Surg Am. 2015; 97(17): 1386-97.

2. Pas HI, Winters M, Haisma HJ, Koenis MJ, Tol JL, Moen MH. Stem cell injections in knee osteoarthritis: a systematic review of the literature. Br J Sports Med. 2017; 51(15): 1125-33. 
3. Rabago D, Kansariwala I, Marshall D, Nourani B, Stiffler-Joachim M, Heiderscheit B. Dextrose Prolotherapy for Symptomatic Knee Osteoarthritis: Feasibility, Acceptability, and Patient-Oriented Outcomes in a PilotLevel Quality Improvement Project. J Altern Complement Med.2019; 25(4): 406-12.

4. Wang Z, Zeng Y, She W, Luo X, Cai L. Is opening-wedge high tibial osteotomy superior to closing-wedge high tibial osteotomy in treatment of unicompartmental osteoarthritis? A meta-analysis of randomized controlled trials. Int J Surg.2018; 60: 153-63.

5. Nerhus TK, Ekeland A, Solberg G, Sivertsen EA, Madsen JE, Heir S. Radiological outcomes in a randomized trial comparing opening wedge and closing wedge techniques of high tibial osteotomy. Knee Surg Sports Traumatol Arthrosc. 2017; 25(3): 910-17.

6. Duivenvoorden T, van Diggele P, Reijman M, et al. Adverse events and survival after closing- and openingwedge high tibial osteotomy: a comparative study of 412 patients. Knee Surg Sports Traumatol Arthrosc. 2017; 25(3): 895-901.

7. Kuwashima U, Tashiro Y, Okazaki K, et al. Comparison of the impact of closing wedge versus opening wedge high tibial osteotomy on proximal tibial deformity and subsequent revision to total knee arthroplasty. Knee Surg Sports Traumatol Arthrosc. 2017; 25(3): 869-75.

8. Li S, Lu Q, Guo X, et al. Intravenous Combined with Topical Tranexamic Acid Administration Has No Additional Benefits Compared with Intravenous Administration Alone in High Tibial Osteotomy: A Retrospective Case-Control Study. Orthop Surg 2020;12(2):515-23.

9. Suh DW, Kyung BS, Han SB, Cheong K, Lee WH. Efficacy of Tranexamic Acid for Hemostasis in Patients Undergoing High Tibial Osteotomy. J Knee Surg. 2018; 31(1): 50-5.

10. Li S, Yang J, Watson C, et al. Drainage relieves pain without increasing post-operative blood loss in high tibial osteotomy: a prospective randomized controlled study.Int Orthop.2020;44(6):1037-43.

11. Martin R, Birmingham TB, Willits K, Litchfield R, Lebel ME, Giffin JR. Adverse event rates and classifications in medial opening wedge high tibial osteotomy. Am J Sport Med. 2014; 42(5): 1118-26.

12. Furuta $Y$, Nakamura $Y$, Tokida $M$, et al. Pre-operative autologous blood donation and transfusion-related adverse reactions: A 14-year experience at a university hospital. Transfus Apher Sci 2018.2018; 57(5): 6515.

13. Franchini M, Liumbruno GM. The key role of tranexamic acid in Patient Blood Management programmes. Blood Transfus.2018; 16(6): 471-2.

14. Desai N, Schofield N, Richards T. Perioperative Patient Blood Management to Improve Outcomes. Anesth Analg .2018; 127(5): 1211-20.

15. Liu Q, Geng P, Shi L, Wang Q, Wang P. Tranexamic acid versus aminocaproic acid for blood management after total knee and total hip arthroplasty: A systematic review and meta-analysis. Int J Surg 2018; 54(Pt A): 105-12.

16. Hariharan D, Mammi M, Daniels K, et al. The Safety and Efficacy of Tranexamic Acid in Adult Spinal Deformity Surgery: A Systematic Review and Meta-Analysis. Drugs. 2019; 79(15): 1679-88.

17. Yao RZ, Gao WQ, Wang BW, Wang GL, Wu CX, YD AM. Efficacy and Safety of Tranexamic Acid in Reducing Blood Loss of Lower Extremity Osteotomy in Peri-acetabulum and High Tibia: A Systematic Review and Meta-analysis. Orthop Surg.2019; 11(4): 545-51. 
18. Palanisamy JV, Das S, Moon KH, Kim DH, Kim TK. Intravenous Tranexamic Acid Reduces Postoperative Blood Loss After High Tibial Osteotomy. Clin Orthop Relat Res. 2018; 476(11): 2148-54.

19. Kim KI, Kim HJ, Kim GB, Bae SH. Tranexamic acid is effective for blood management in open-wedge high tibial osteotomy. Orthop Traumatol Surg Res.2018; 104(7): 1003-7.

20. Tzatzairis T, Drosos GI, Vogiatzaki T, Tilkeridis K, Ververidis A, Kazakos K. Multiple intravenous tranexamic acid doses in total knee arthroplasty without tourniquet: a randomized controlled study. Arch Orthop Trauma Surg. 2019; 139(6): 859-68.

21. Petersen W, Metzlaff S. Open wedge high tibial osteotomy (HTO) versus mobile bearing unicondylar medial joint replacement: five years results. Arch Orthop Trauma Surg.2016; 136(7): 983-9.

22. Mayhew D, Mendonca V, Murthy BVS. A review of ASA physical status - historical perspectives and modern developments. Anaesthesia.2019; 74(3): 373-9.

23. Kohn MD, Sassoon AA, Fernando ND. Classifications in Brief: Kellgren-Lawrence Classification of Osteoarthritis. Clin Orthop Relat Res.2016; 474(8): 1886-93.

24. Cao G, Xie J, Huang Z, et al. Efficacy and safety of multiple boluses of oral versus intravenous tranexamic acid at reducing blood loss after primary total knee arthroplasty without a tourniquet: A prospective randomized clinical trial. Thromb Res.2018; 171: 68-73.

25. Yates J, Perelman I, Khair S, et al. Exclusion criteria and adverse events in perioperative trials of tranexamic acid: a systematic review and meta-analysis. Transfusion.2019; 59(2): 806-24.

26. Wang W, Liu L, Chang X, Jia ZY, Zhao JZ, Xu WD. Cross-cultural translation of the Lysholm knee score in Chinese and its validation in patients with anterior cruciate ligament injury. BMC musculoskeletal disorders.2016; 17(1): 436.

27. Clement ND, Weir D, Holland J, Gerrand C, Deehan DJ. Meaningful changes in the Short Form 12 physical and mental summary scores after total knee arthroplasty. Knee.2019; 26(4): 861-8.

28. Kjeldsen HB, Klausen TW, Rosenberg J. Preferred Presentation of the Visual Analog Scale for Measurement of Postoperative Pain. Pain Pract.2016; 16(8): 980-4.

29. Nadler SB, Hidalgo JH, Bloch T. Prediction of blood volume in normal human adults. Surgery. 1962; 51(2): 224-32.

30. Gross JB. Estimating allowable blood loss: corrected for dilution. Anesthesiology.1983; 58(3): $277-80$.

31. Xiao C, Zhang S, Long N, Yu W, Jiang Y. Is intravenous tranexamic acid effective and safe during hip fracture surgery? An updated meta-analysis of randomized controlled trials. Arch Orthop Trauma Surg.2019; 139(7): 893-902.

32. Alburaih A. Tranexamic Acid (TXA) in Trauma Patients: Barriers to Use among Trauma Surgeons and Emergency Physicians. Emerg Med Int.2017; 2017: 4235785.

33. Lee WS, Kim KI, Lee HJ, Kyung HS, Seo SS. The incidence of pulmonary embolism and deep vein thrombosis after knee arthroplasty in Asians remains low: a meta-analysis. Clin Orthop Relat Res.2013; 471(5): 1523-32.

34. Zhang S, Huang Q, Xu B, Ma J, Cao G, Pei F. Effectiveness and safety of an optimized blood management program in total hip and knee arthroplasty: A large, single-center, retrospective study. Medicine. 2018; 97(1): e9429. 
35. Jules-Elysee KM, Tseng A, Sculco TP, et al. Comparison of Topical and Intravenous Tranexamic Acid for Total Knee Replacement: A Randomized Double-Blinded Controlled Study of Effects on Tranexamic Acid Levels and Thrombogenic and Inflammatory Marker Levels. J Bone Joint Surg Am. 2019;101(23):2120-8.

36. Barrett CD, Moore HB, Kong YW, et al. Tranexamic acid mediates proinflammatory and anti-inflammatory signaling via complement $\mathrm{C} 5$ a regulation in a plasminogen activator-dependent manner. J Trauma Acute Care Surg.2019; 86(1): 101-7.

37. Carroll K, Dowsey M, Choong P, Peel T. Risk factors for superficial wound complications in hip and knee arthroplasty. Clin Microbiol Infect.2014; 20(2): 130-5.

\section{Figures}

\section{Estimated blood loss and drainage volume}

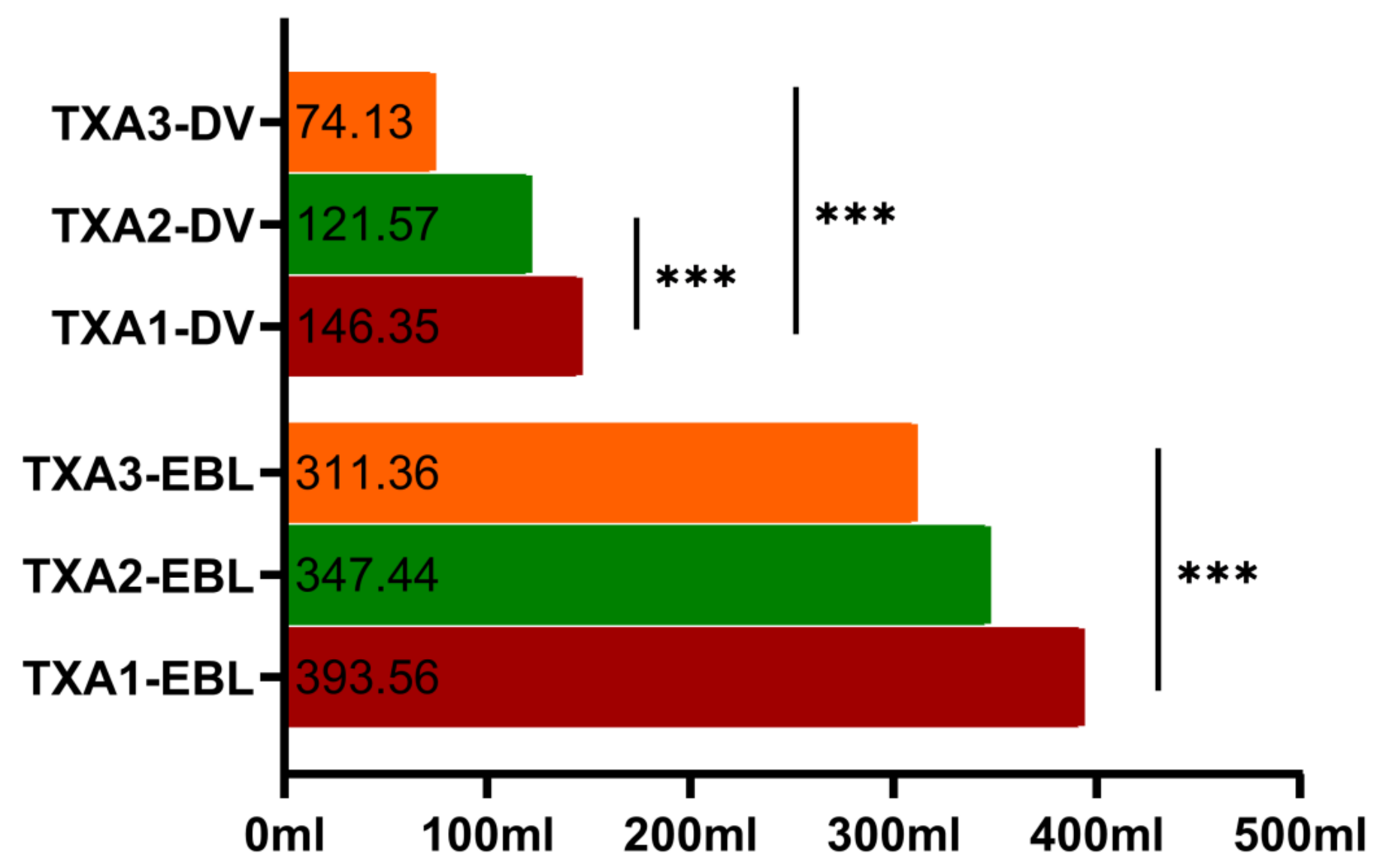

Figure 1

Estimated blood loss and drainage volume comparison between the three groups. Abbreviations: DV, drainage volume. EBL estimated blood loss. P1 represents the $p$-value obtained by comparison between TXA1 and TXA2; 
P2 represents the $p$-value obtained by comparison between TXA1 and TXA3; P3 represents the p-value obtained by comparison between TXA2 and TXA3; Intergroup comparisons performed using the AVONA test. TXA2 group and TXA3 group have advantages in reducing postoperative drainage volume compared to those in the TXA1 group ( $p$-value $<0.001$ ), but no statistical difference can be observed between the TXA2 group and the TXA3 group. The TXA3 group reduced the estimated blood loss most significantly.

\section{LKS score}

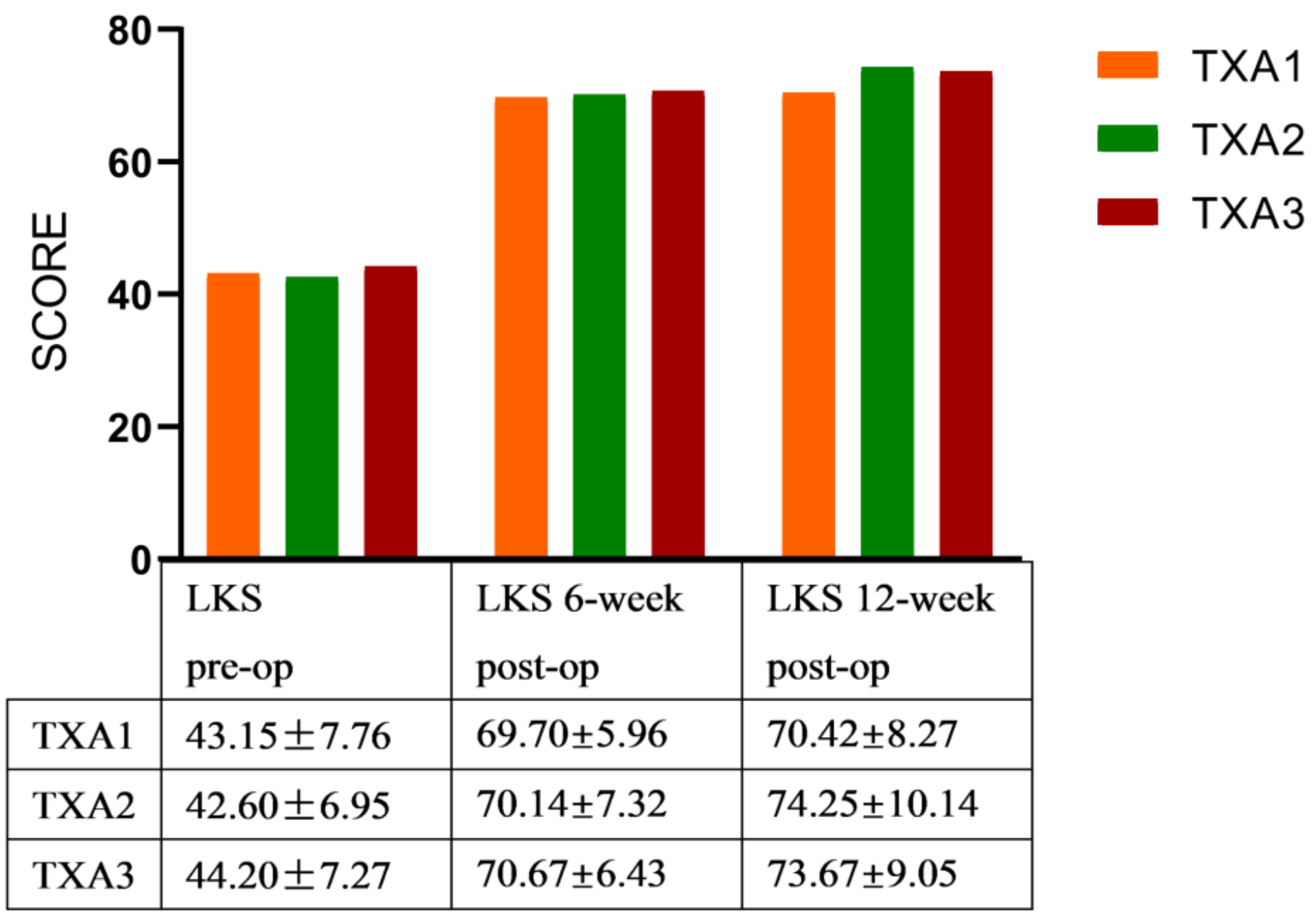

Figure 2

LKS score comparison between the three groups No difference can be observed between the three groups at given time points. 


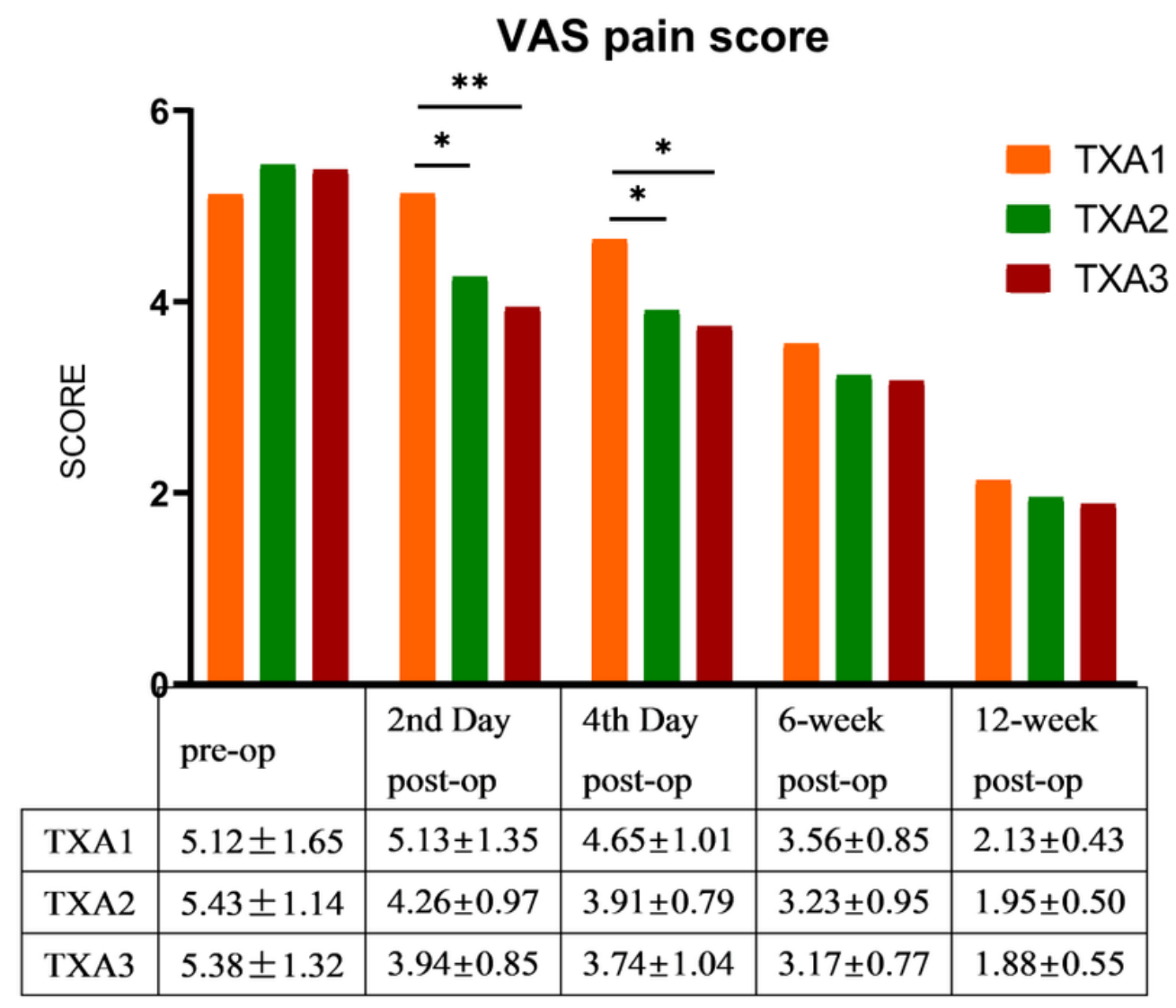

Figure 3

VAS pain scores comparison between the three groups $\mathrm{P} 1$ represents the $\mathrm{p}$-value obtained by comparison between TXA1 and TXA2; P2 represents the $p$-value obtained by comparison between TXA1 and TXA3; P3 represents the p-value obtained by comparison between TXA2 and TXA3; Intergroup comparisons performed using the AVONA test. 2nd Day post-op: P1『0.05; P2『0.01. 4th Day post-op: P1ख0.05; P2『0.05. 


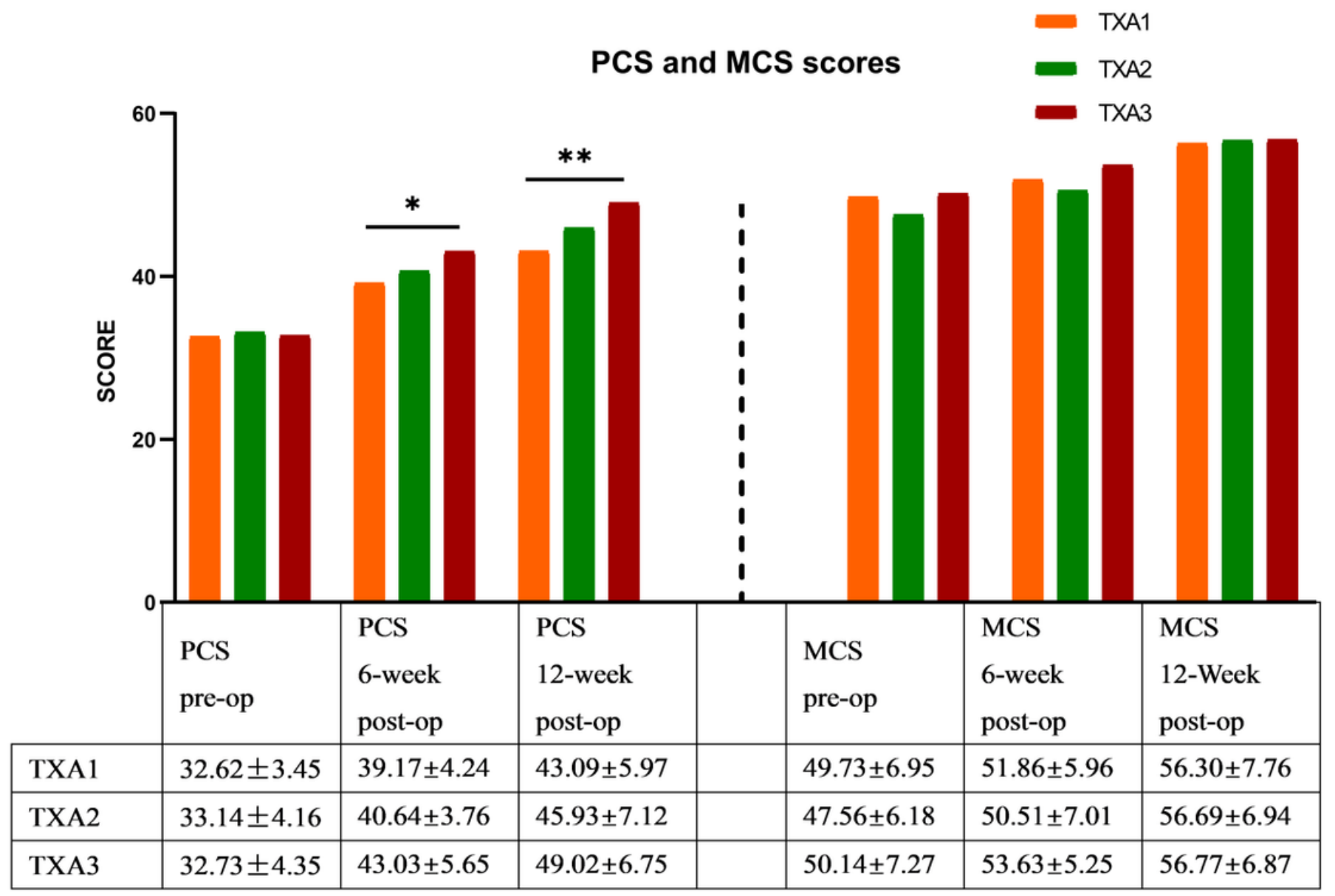

Figure 4

SF-12 PCS and MCS scores comparison between the three groups P1 represents the p-value obtained by comparison between TXA1 and TXA2; P2 represents the p-value obtained by comparison between TXA1 and TXA3; P3 represents the $p$-value obtained by comparison between TXA2 and TXA3; Intergroup comparisons performed using the AVONA test. The TXA3 group's PCS was significantly higher than the TXA1 group at 6 weeks and 12 weeks post-op(p囚0.05 and $\mathrm{p} \bigotimes 0.01$, respectively). 